\title{
Absence of MGMT promoter methylation in diffuse midline glioma, H3 K27M-mutant
}

\author{
Rouzbeh Banan ${ }^{1}$, Arne Christians ${ }^{1}$, Stephan Bartels ${ }^{2}$, Ulrich Lehmann ${ }^{2}$ and Christian Hartmann ${ }^{1 *}$
}

Keywords: Diffuse midline glioma H3 K27M-mutant, H3F3A, HIST1H3B, MGMT

\section{Letter}

According to the revised 4th edition of the WHO classification of tumors of the CNS, diffuse midline gliomas, H3 K27M-mutant (DMG) are molecularly defined as tumors with a predominantly astrocytic differentiation carrying mutations in the histone $\mathrm{H} 3$ encoding genes H3F3A (histone H3.3), HIST1H3B (H3.1) or HIST1H3C (H3.2) [9]. The vast majority of DMG demonstrate typical features of glioblastomas WHO grade IV (GBM): Malignant astrocytic morphology, necrosis and/ or microvascular proliferation. However, due to the poor clinical course of patients with DMG these tumors are assigned WHO grade IV irrespectively of GBM features. DMG are usually observed in children and young adults and occur in midline structures like thalamus, brainstem and spinal cord [9]. Most DMG carry H3F3A mutations; a smaller fraction shows $H I S T 1 H 3 B$ alterations, whereas HIST1H3C and, as recently shown, HIST2H3C mutations were identified only in single cases [10]. Around $80 \%$ of all diffuse intrinsic pontine gliomas (DIPG) exhibit the molecular profile of DMG [8]. Surgical intervention in DMG is often challenging and may lead to incomplete resection or even unsuccessful attempt failing to do a biopsy in many cases. Thus, radiotherapy and chemotherapy have a significant therapeutic importance in these patients compared with those with supratentorial GBM. Nowadays most patients with GBM receive radiotherapy and concomitant/adjuvant chemotherapy with temozolomide (TMZ) [1]. Around $40 \%$ of these cases feature hypermethylation of the promoter region of O-6-methylguanine DNA methyltransferase (MGMT) gene showing a positive response to TMZ

\footnotetext{
* Correspondence: hartmann.christian@mh-hannover.de; https://www.mhhannover.de/pathologie-neuropat.html

${ }^{1}$ Institute of Pathology, Department of Neuropathology, Hannover Medical School (MHH), Carl-Neuberg-Str. 1, D-30625 Hannover, Germany Full list of author information is available at the end of the article
}

treatment in comparison to those with absent MGMT methylation [1]. The MGMT gene on the chromosomal arm 10q26 consists of five exons and a CpG-rich island with $98 \mathrm{CpG}$ sites covering exon 1 and most parts of the promoter (Fig. 1). Since CpG methylation pattern is not always homogenous, distinct assays may lead to conflicting results depending on the CpG sites analyzed [13]. For further understanding the contribution of each of the $98 \mathrm{CpG}$ sites to MGMT expression, different studies have focused on sequencing large areas of the $\mathrm{CpG}$ island. By analyzing glioma cells without MGMT expression upstream and downstream highly methylated regions (UHMR, DHMR) were identified in the $\mathrm{CpG}$ island as well as a region in between containing a varying methylation rate (Fig. 1) [11]. Furthermore, through analyzing $52 \mathrm{CpG}$ sites, the methylation status of six CPG sites was found to highly correlate with $M G M T$ mRNA expression (Fig. 1) [5]. Because of the GBM-like histological appearance of most DMG, patients receive in many institutions the same treatment as those with supratentorial GBM. However, the MGMT promoter methylation status has not systematically been studied in patients with DMG and only few data have been reported so far $[2,3,7,12]$.

To clarify the frequency of MGMT promoter methylation in DMG we analyzed a retrospective series of 143 astrocytic midline tumors for $H 3 F 3 A$ and $H I S T 1 H 3 B$ codon 27 mutations by pyrosequencing ( $\mathrm{MHH}$ ethic board vote \#1707-2013 \& \#6960). We identified H3F3A K27M mutations in 46/143 tumors including 25 males (54\%) and 21 females (46\%) with a median age of 23 at diagnosis and a range of $1-68$ years. No HIST1H3B mutation was found. Next, we tested these 46 DMG for $M G M T$ promoter methylation. For this purpose, DNA underwent bisulfite treatment and $14 \mathrm{CpG}$ sites in the distal promoter region were analyzed by pyrosequencing (Fig. 1). A mean methylation level of $10 \%$ was defined as 


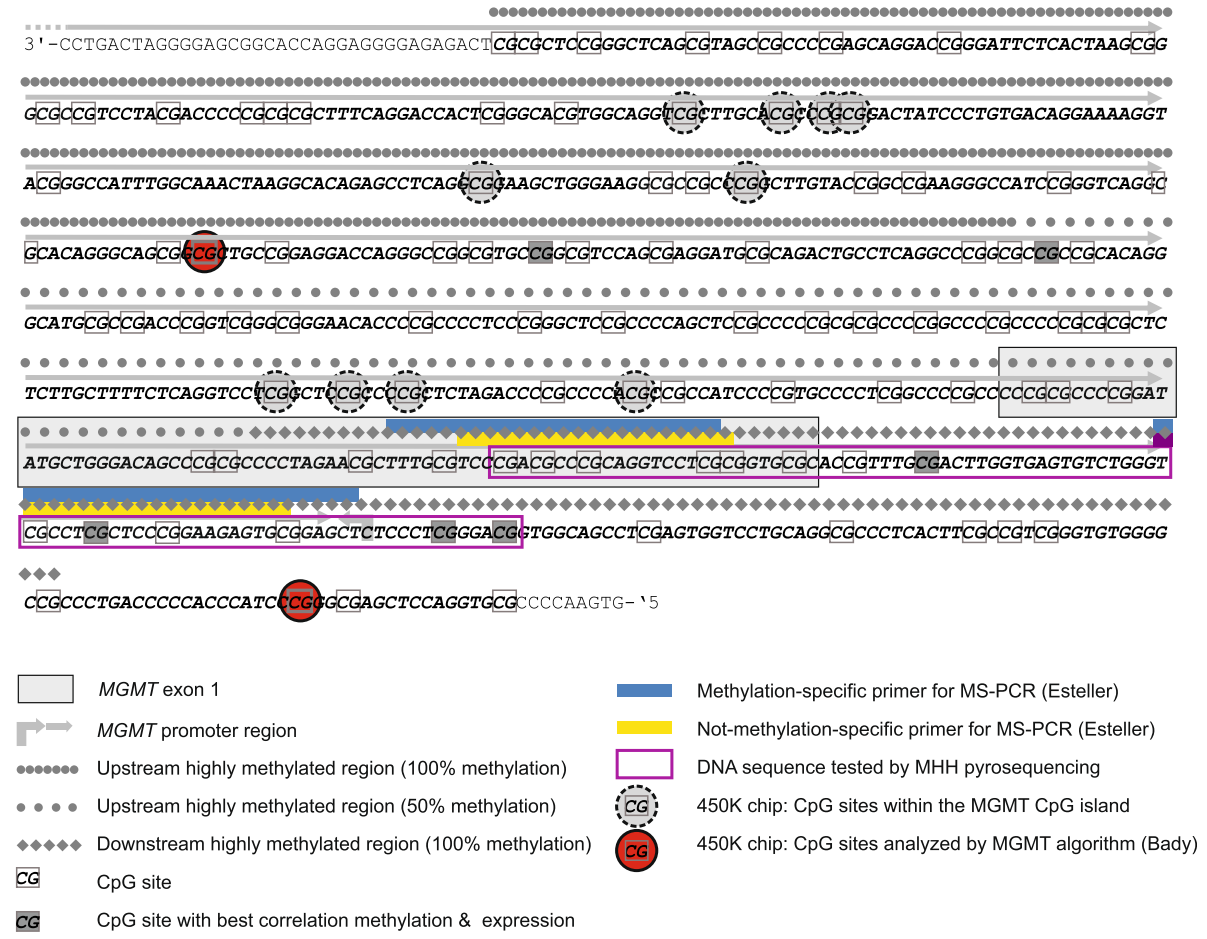

Fig. 1 Genomic structure of the MGMT promoter. The CpG island covers the major part of the promoter region including Exon 1. The two CpG sites analyzed by the Illumina $450 \mathrm{~K}$ array (highlighted in red) are not associated with the DHMR as the common target region in the routinely performed assays using MS-PCR and Pyrosequencing. Our newly designed pyrosequencing assay (purple box) targets the distal section of the promoter overlapping DHMR and includes $4 / 6 \mathrm{CpG}$ sites that highly correlate with MGMT mRNA expression

threshold for hypermethylation. Not a single DMG showed MGMT promoter hypermethylation. To compare this result with the methylation rate in none-DMG GBM we evaluated MGMT-promoter methylation in 40 cases of midline GBM without H3 K27M-alterations showing a hypermethylation status in 14 cases $(35 \%)$ and absence of methylation in 26 tumors (65\%). We, moreover, performed the same analysis in another control group of 247 patients with supratentorial GBM, IDH-wildtype that revealed hypermethylation in 94 tumors (38\%) vs. 153 cases (62\%) lacking MGMT hypermethylation.

Only few reports are available analyzing MGMT status in DIPG or DMG. First, Babu et al. published a series of five adult patients with DIPG. Using immunohistochemistry, they found MGMT expression in all tumors [3]. Later, the same group reported an MGMT expression frequency of $64.7 \%$ in a cohort of 34 patients with DIPG [2], while the $\mathrm{H} 3$ mutation status remained unknown. These findings might imply that in most adult DIPG patients the tumor carries no $M G M T$ methylation. In another study, Reyes-Botero et al. found no MGMT promoter methylation in three adult patients with infratentorial DMG [12]. Using the Illumina $450 \mathrm{~K}$ methylation platform, 3/69 pediatric patients with DMG (4\%) exhibited hypermethylation of the CpG site in the MGMT promoter [7]. However, only two of the $98 \mathrm{CpG}$ sites of the MGMT CpG island are subject of analysis by the commonly applied algorithm [4] to filter $450 \mathrm{~K}$ data for MGMT promoter methylation (Fig. 1). A direct comparison between such $450 \mathrm{~K}$ based MGMT data and results of MS-PCR has demonstrated a good correlation [4]. Nevertheless, these two CpG sites are not located within the DHMR which is commonly analyzed by most neuropathology departments by MS-PCR or pyrosequencing [13] and has been shown to be strongly associated with the predictive role of $M G M T$ promoter methylation according to the responsible CpG sites in this area (Fig. 1) [6]. To overcome this technical limitation of $450 \mathrm{~K}$ MGMT analysis we designed a pyrosequencing assay focusing on the DHMR [11] encompassing 4/6 CpG sites found to highly correlate with MGMT mRNA expression [5]. Therefore, we assume that the results of our study are more comparable with MGMT promoter methylation results of those neurooncology laboratories where $450 \mathrm{~K}$ technology is not available yet.

We had a median age of 23 years at diagnosis in DMP patients of our study with 9 patients aged 40 years or older including one 54- and one 68-yearold patient. These older ages of tumor occurrence in H3 K27M-mutant tumors are unusual, as these tumors have been reported to occur mostly at younger ages $[10,14]$. 
In summary, our results and the published data clearly indicate that MGMT promoter methylation is a rare event in DMG patients supporting the idea that analyzing the MGMT promoter status would only be recommended in H3 K27M-wildtype GBM. Based on the concept that MGMT promoter hypermethylation is associated with a better response to TMZ through reduced expression of MGMT protein, our observation might also explain the failure of clinical trials administrating TMZ to patients with DIPG [8].

\section{Acknowledgements}

We wish to thank Wiebke Schulze for skillful technical assistance.

\section{Authors' contributions}

RB conceptual design, database retrieval, molecular analysis, analyzing the data, writing the manunscript. AC molecular analysis, writing the manunscript. SB molecular analysis, writing the manunscript. UL molecular analysis, writing the manunscript. $\mathrm{CH}$ conceptual design, database retrieval, analyzing the data, writing the manunscript.

\section{Competing interests}

The authors declare that they have no competing interests.

\section{Publisher's Note}

Springer Nature remains neutral with regard to jurisdictional claims in published maps and institutional affiliations.

\section{Author details}

'Institute of Pathology, Department of Neuropathology, Hannover Medical School (MHH), Carl-Neuberg-Str. 1, D-30625 Hannover, Germany. ${ }^{2}$ Institute of Pathology, Hannover Medical School, Hannover, Germany.

Received: 24 November 2017 Accepted: 24 November 2017

Published online: 15 December 2017

\section{References}

1. Aldape K, Zadeh G, Mansouri S, Reifenberger G, von Deimling A (2015) Glioblastoma: pathology, molecular mechanisms and markers. Acta Neuropathol 129:829-848. doi: 10.1007/s00401-015-1432-1

2. Babu R, Kranz PG, Agarwal V, McLendon RE, Thomas S, Friedman AH, Bigner DD, Adamson C (2014) Malignant brainstem gliomas in adults: clinicopathological characteristics and prognostic factors. J Neuro-Oncol 119:177-185. doi: 10.1007/s11060-014-1471-9

3. Babu R, Kranz PG, Karikari IO, Friedman AH, Adamson C (2013) Clinical characteristics and treatment of malignant brainstem gliomas in elderly patients. J Clin Neurosci 20:1382-1386. doi: 10.1016/j.jocn.2012.12.011

4. Bady P, Sciuscio D, Diserens AC, Bloch J, van den Bent MJ, Marosi C, Dietrich PY, Weller M, Mariani L, Heppner FL et al (2012) MGMT methylation analysis of glioblastoma on the Infinium methylation BeadChip identifies two distinct $\mathrm{CpG}$ regions associated with gene silencing and outcome, yielding a prediction model for comparisons across datasets, tumor grades, and CIMP-status. Acta Neuropathol 124:547-560. doi: 10.1007/s00401-012-1016-2

5. Everhard S, Tost J, El Abdalaoui H, Criniere E, Busato F, Marie Y, Gut IG, Sanson M, Mokhtari K, Laigle-Donadey F et al (2009) Identification of regions correlating MGMT promoter methylation and gene expression in glioblastomas. Neuro-Oncology 11:348-356. doi: 10.1215/15228517-2009-001

6. Hegi ME, Diserens AC, Gorlia T, Hamou MF, de Tribolet N, Weller M, Kros JM, Hainfellner JA, Mason W, Mariani L et al (2005) MGMT gene silencing and benefit from temozolomide in glioblastoma. N Engl J Med 352:997-1003. doi: 10.1056/NEJMoa043331

7. Korshunov A, Ryzhova M, Hovestadt V, Bender S, Sturm D, Capper D, Meyer J, Schrimpf D, Kool M, Northcott PA et al (2015) Integrated analysis of pediatric glioblastoma reveals a subset of biologically favorable tumors with associated molecular prognostic markers. Acta Neuropathol 129:669-678. doi: 10.1007/s00401-015-1405-4

8. Lapin DH, Tsoli M, Ziegler DS (2017) Genomic insights into diffuse intrinsic Pontine Glioma. Front Oncol 7:57. doi: 10.3389/fonc.2017.00057
9. Louis DN, Ohgaki H, Wiestler OD, Cavenee WK, Ellision DW, Figarella-Branger D, Reifenberger G, von Deimling A (2016) WHO classification and grading of tumours of the central nervous system. IARC Press; International Agency for Research on Cancer, City, Lyon

10. Mackay A, Burford A, Carvalho D, Izquierdo E, Fazal-Salom J, Taylor KR, Bjerke L, Clarke M, Vinci M, Nandhabalan M et al (2017) Integrated molecular meta-analysis of 1,000 pediatric high-grade and diffuse intrinsic Pontine Glioma. Cancer Cell 32:520-537 e525. doi: 10.1016/j.ccell.2017.08.017

11. Nakagawachi T, Soejima H, Urano T, Zhao W, Higashimoto K, Satoh Y, Matsukura S, Kudo S, Kitajima Y, Harada H et al (2003) Silencing effect of $\mathrm{CpG}$ island hypermethylation and histone modifications on O6methylguanine-DNA methyltransferase (MGMT) gene expression in human cancer. Oncogene 22:8835-8844. doi: 10.1038/sj.onc.1207183

12. Reyes-Botero G, Giry M, Mokhtari K, Labussiere M, Idbaih A, Delattre JY, Laigle-Donadey F, Sanson M (2014) Molecular analysis of diffuse intrinsic brainstem gliomas in adults. J Neuro-Oncol 116:405-411. doi: 10.1007/s11060-013-1312-2

13. von Deimling A, Korshunov A, Hartmann C (2011) The next generation of glioma biomarkers: MGMT methylation, BRAF fusions and IDH1 mutations. Brain Pathol 21:74-87. doi: 10.1111/j.1750-3639.2010.00454.x
Submit your next manuscript to BioMed Central and we will help you at every step:

- We accept pre-submission inquiries

- Our selector tool helps you to find the most relevant journal

- We provide round the clock customer support

- Convenient online submission

- Thorough peer review

- Inclusion in PubMed and all major indexing services

- Maximum visibility for your research

Submit your manuscript at www.biomedcentral.com/submit
) Biomed Central 